\title{
Cephalic tetanus: demonstration of a dual lesion
}

\author{
F. D. D A S T UR, M. T. SHA H A I, D. H. D A S T O O R, \\ F. N. K O H I Y A R, E. P. B H A R U CH A, V. P. MO N D K R , \\ G. H. K A S H Y A P, A N D K. G . N A I R
}

From the Department of Medicine and Neurology, King Edward VII Memorial Hospital, and the Institute of Electrophysiology, Seth GS Medical College, Bombay, India

S U M M A R Y A clinical and electrophysiological study of 15 cases of cephalic tetanus is reported. This condition is a form of local tetanus which commonly follows an injury to the face or head. It is characterised by muscle paralysis which is maximal close to the site of injury, while spasm is evident at more distant sites. As muscle paralysis improves with time it is succeeded by spasm. It is argued that paralysis is due to high local concentrations of toxin in the brainstem while lesser concentrations cause spasm by abolishing inhibition. Electrophysiological studies indicate that paralysis is of lower motor neurone type with denervation potentials, hyperirritability, loss of motor units, and marginally increased distal latencies being the features recorded.

Cephalic tetanus is an unusual form of tetanus characterised by the presence of local muscle paralysis. Affected individuals usually have an injury to the face or head but this is not invariable. The typical features of tetanus occur together with paralysis of muscles supplied by one or more cranial nerves. The condition thus defined has been extended in the present discussion to include cases with no paralysis but in whom disproportionately severe muscle spasm is seen on the side of injury to the face or head.

Tetanus toxin (tetanospasmin) in sublethal doses acts to abolish neuronal inhibition in the spinal cord (Brooks et al., 1957). Histology shows that larger doses produce changes of chromatolysis in the anterior horn cells (Tarlov et al., 1973). Electrophysiological and ultrastructural studies indicate an additional action of toxin at the neuromuscular junction, where it interferes with the release of neurotransmitter substance (Kaeser and Saner, 1970; Mellanby and Thompson, 1972; Duchen and Tonge, 1972). This knowledge of the actions of toxin has not provided an explanation for the nature or location of the lesion of cephalic tetanus (Achari, 1973). We report here results of a clinical and electrophysiological study which provide new data on the genesis of this syndrome.

Address for reprint requests: Dr F. D. Dastur, Seth GS Medical College and King Edward VII Memorial Hospital, Parel, Bombay-400012, India.

Accepted 22 February 1977

\section{Patients}

Fifteen cases of cephalic tetanus, representing $1.5 \%$ of all cases admitted to the tetanus ward during an 18 month period, are reported. In 14 , the cause was injury to the head or face, and in one unknown. In 14 cases the presenting symptom was lockjaw. In the remaining case the patient had hemifacial spasm which remained undiagnosed for a week until lockjaw developed. All patients had involvement of the facial nerve, four had hemifacial spasm, four unilateral facial paresis, and one bilateral facial paresis. In the remaining six cases some facial muscles showed weakness and other overactivity, both occurring at the same time (Table 1). In no case were external ocular movements affected. Treatment included wound toilet, penicillin, antitetanus serum 10000 IU intravenously, and sedatives and muscle relaxants as required. In four cases tetanus became generalised. One case proved fatal, giving a mortality of $6.6 \%$, as compared to an overall mortality of $30 \%$ during the same period.

\section{CLINICAL FEATURES}

Paralytic signs followed a set pattern. In the distribution of the facial nerve maximum paralysis was always in the muscle closest to the injury. When paralysis at the site of injury was incomplete, distant muscles supplied by the same nerve were either normal or in spasm. When weakness on the opposite side of the face occurred, it was 
Table 1 The changing pattern of clinical involvement of the VIIth cranial nerve in six cases of cephalic tetanus

\begin{tabular}{|c|c|c|c|c|c|c|c|c|c|c|c|}
\hline \multirow{2}{*}{$\begin{array}{l}\text { Case no. } \\
5\end{array}$} & \multicolumn{3}{|c|}{ Name/Age (yr)/Sex } & \multirow{2}{*}{$\begin{array}{l}\text { Site of injury } \\
\text { Left cheek }\end{array}$} & \multicolumn{2}{|c|}{$\begin{array}{c}\text { Signs on admission } \\
\qquad t\end{array}$} & $L t$ & \multicolumn{2}{|c|}{$\begin{array}{l}\text { Signs after } 15 \text { days } \\
R t\end{array}$} & \multicolumn{2}{|c|}{$\begin{array}{l}\text { Denervation } \\
\text { activity on } \\
\text { EMG }\end{array}$} \\
\hline & $\mathbf{S M}$ & 35 & $\mathbf{M}$ & & $\begin{array}{l}\text { Fr } \\
\text { Oc } \\
\text { Or }\end{array}$ & $\stackrel{+}{\mathbf{N}}$ & $\begin{array}{l}-- \\
-- \\
-\end{array}$ & $\begin{array}{l}+ \\
\mathbf{N} \\
\mathbf{N}\end{array}$ & $\begin{array}{l} \pm \\
\pm \\
\pm\end{array}$ & $\begin{array}{l}\text { Yes } \\
\text { No } \\
\text { No }\end{array}$ & $\begin{array}{l}\text { Yes } \\
\text { Yes } \\
\text { Yes }\end{array}$ \\
\hline 7 & SL & 45 & $\mathbf{F}$ & Right temple & $\begin{array}{l}\text { Fr } \\
\text { Oc } \\
\text { Or }\end{array}$ & $\begin{array}{l}-- \\
\pm \\
\pm\end{array}$ & $\stackrel{+}{\mathbf{N}}$ & $\begin{array}{l} \pm \\
\pm+ \\
+\end{array}$ & $\begin{array}{l} \pm \\
\pm \\
+ \\
+\end{array}$ & $\begin{array}{l}\text { Yes } \\
\text { No } \\
\text { No }\end{array}$ & $\begin{array}{l}\text { Yes } \\
\text { No } \\
\text { No }\end{array}$ \\
\hline 10 & GK & 30 & $\mathbf{M}$ & Left eyebrow & $\begin{array}{l}\text { Fr } \\
\text { Oc } \\
\text { Or }\end{array}$ & $\begin{array}{l} \pm \\
\overline{\mathbf{N}}\end{array}$ & $\begin{array}{l}-- \\
--\end{array}$ & $\begin{array}{l} \pm \\
\pm \\
t\end{array}$ & $\frac{-}{ \pm}$ & $\begin{array}{l}\text { No } \\
\text { No } \\
\text { No }\end{array}$ & $\begin{array}{l}\text { Yes } \\
\text { No } \\
\text { No }\end{array}$ \\
\hline 11 & JD & 50 & $\mathbf{M}$ & Left zygoma & $\begin{array}{l}\mathrm{Fr} \\
\mathrm{Oc} \\
\mathrm{Or}\end{array}$ & $\begin{array}{l}\mathbf{N} \\
\mathbf{N} \\
\mathbf{N}\end{array}$ & $\begin{array}{l}+ \\
++ \\
+\end{array}$ & $\begin{array}{l}+ \\
\pm \\
\mathbf{N}\end{array}$ & $\begin{array}{l} \pm \\
+ \\
+\end{array}$ & $\begin{array}{l}\text { No } \\
\text { Yes } \\
\text { No }\end{array}$ & $\begin{array}{l}\text { No } \\
\text { No } \\
\text { No }\end{array}$ \\
\hline 12 & MH & 40 & $\mathbf{M}$ & Forehead right of centre & $\begin{array}{l}\text { Fr } \\
\text { Oc } \\
\text { Or }\end{array}$ & $\begin{array}{l}-- \\
\pm \\
\pm\end{array}$ & $\begin{array}{l}-- \\
\pm \\
\mathbf{N}\end{array}$ & $\begin{array}{l} \pm \\
+ \pm \\
\pm\end{array}$ & $\begin{array}{l} \pm \\
\pm \\
\mathbf{N}\end{array}$ & $\begin{array}{l}\text { Yes } \\
\text { No } \\
\text { Yes }\end{array}$ & $\begin{array}{l}\text { Yes } \\
\text { No } \\
\text { No }\end{array}$ \\
\hline 14 & RS & 38 & $\mathbf{M}$ & Right forehead & $\begin{array}{l}\text { Fr } \\
\text { Oi } \\
\text { Or }\end{array}$ & $\begin{array}{l}-- \\
\pm \\
+\end{array}$ & $\begin{array}{l}-- \\
\bar{N}\end{array}$ & $\begin{array}{l} \pm- \\
+ \pm \\
+\end{array}$ & $\begin{array}{l}\overline{+} \\
+ \\
+\end{array}$ & $\begin{array}{l}\text { Yes } \\
\text { Yes } \\
\text { No }\end{array}$ & $\begin{array}{l}\text { Yes } \\
\text { Yes } \\
\text { No }\end{array}$ \\
\hline
\end{tabular}

$\mathbf{F r}=$ Frontalis. $\mathbf{O c}=$ Orbicularis oculi. Or $=$ Orbicularis oris. + Overactive. ++ Strongly overactive. - Weak. -- Paralysed. \pm Overactive and weak. $\mathbf{N}=$ normal.

less severe than on the side of injury (Table 1).

Facial muscles, which initially showed weakness, later changed to a state of spasm before eventually returning to normal. A period, therefore, occurred when both weakness and spasm were evident in a single muscle.

This sequence of events was readily predictable and seen in every case. The signs evolved over eight weeks on average. By contrast, the severity of the disease with regard to the number of muscles involved and their degree of paralysis, could not be anticipated, even in cases where the site of injury was identical. This was presumed to be due to different degrees of toxin production.

\section{Methods}

Electromyography (EMG) and nerve conduction studies were performed on Medelec MS4 and MS6 models using concentric needle electrodes. All relevant electrophysiological data were photographed in either single shot, continuous, or raster modes as necessary. Muscles from both sides of the face were sampled and activity recorded at rest and on minimal and maximal effort. The evoked potential was examined in the various muscles after stimulation of the facial nerve at the tragus, and the latencies measured. Facial nerve block using $2 \%$ procaine was performed when necessary. Trains of supramaximal stimuli at $50 \mathrm{~s}^{-1}$ were used to assess motor endplate function. The masseters and other muscles were tested where indicated. The whole examination was performed after one week of symptoms, and thereafter at two weekly intervals until resolution of the disease. Where cephalic tetanus was accompanied by generalised disease the examination was deferred.

\section{Results}

Examination of affected muscles at rest distinguished three types of spontaneous activity. The first, an almost invariable feature seen on needle insertion, was action potentials which fired at such frequency and in such numbers as to produce an interference or mixed pattern on the oscilloscope (Fig. 1a). This pattern diminished in density with time but to a variable degree. Activity was abolished by facial nerve block using $2 \%$ procaine and also by light anaesthesia with thiopentone.

The second type of spontaneous activity resembled denervation potentials on applying the accepted criteria of duration, amplitude, shape, and frequency (Fig. 1b). In the presence of other spontaneous activity these could easily be missed unless careful attention was paid to the loudspeaker. Their true nature was confirmed by finding that they persisted after applying nerve block. They were detected only from the end of the first to the end of the sixth week of the disease.

On occasions signals resembling high frequency discharge were recorded and constituted the third type of spontaneous activity seen (Fig. 2).

When muscles showing spontaneous electrical activity were examined on maximal effort, there was augmentation of action potentials with re- 


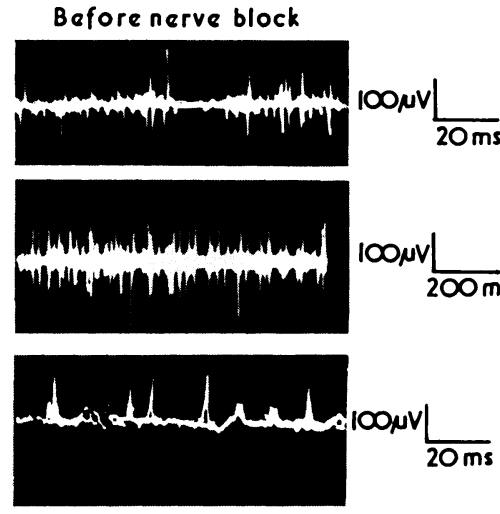

(a)
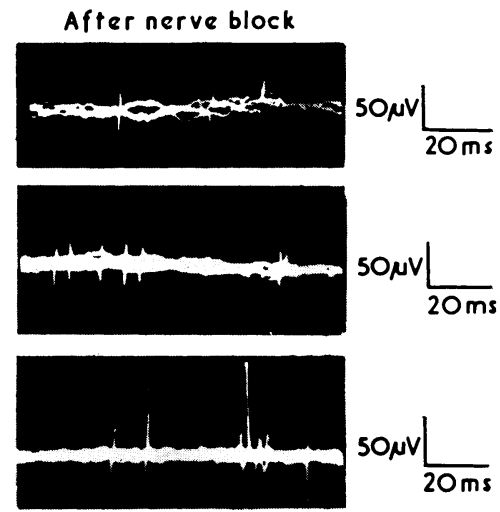

(b)
Fig. 1 Spontaneous activity of frontalis muscle before and after nerve block
Orbicularis oris $\mathrm{m}$.

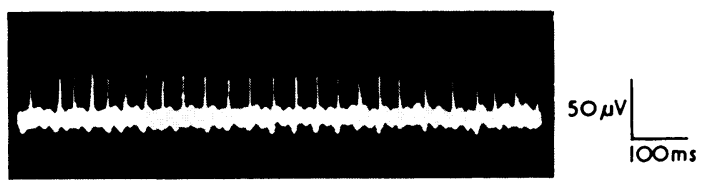

Fig. 2 Spontaneous activity of orbicularis oris muscle.

gard to both amplitude and density. This was not seen if the muscles were significantly weak or paralysed. In such cases it was not possible to obtain a good mixed or interference pattern. Study of motor units recruited by voluntary effort proved difficult on account of the first type of spontaneous activity and it was not possible to comment on them.

The $M$ response was elicited in all cases from the frontalis and orbicularis oris muscles, and also from the orbicularis oculi muscle when this was attempted. Distal latencies were marginally in. creased in about $10 \%$ of cases. Serial studies showed a return to normal within 6 to 12 weeks.

On studying the $M$ response with stimuli at $50 \mathrm{~s}^{1}$, most patients did not show significant change in the amplitude of the potential. In the frontalis muscle of two cases, however, marginal decrement was found. No augmentation occurred after injection of neostigmine. The EatonLambert phenomenon was not encountered.

Table 2 sets out the electromyographic data recorded from a representative case at different stages of the disease.

\section{Discussion}

Clinical analysis has failed to resolve the paradox of cephalic tetanus and the help of electrophysiology has recently been enlisted.

Park (1970) described the EMG findings performed on the 10th day in one of his seven

Table 2 EMG findings from a representative case (12) with precipitating injury to forehead right of midline

\begin{tabular}{|c|c|c|c|c|c|c|c|c|c|}
\hline \multirow{2}{*}{$\begin{array}{l}\text { Duration of } \\
\text { symptoms }\end{array}$} & \multirow[t]{2}{*}{ Muscle examined } & \multicolumn{4}{|l|}{ Right } & \multicolumn{4}{|l|}{ Left } \\
\hline & & $\begin{array}{l}\text { Spontaneous } \\
\text { activity }\end{array}$ & $\begin{array}{l}\text { Denervation } \\
\text { activity }\end{array}$ & $\begin{array}{l}\text { Maximum } \\
\text { effort }\end{array}$ & $\begin{array}{l}\text { Latency } \\
(\mathrm{ms})\end{array}$ & $\begin{array}{l}\text { Spontaneous } \\
\text { activity }\end{array}$ & $\begin{array}{l}\text { Denervation } \\
\text { activity }\end{array}$ & $\begin{array}{l}\text { Maximum } \\
\text { effort }\end{array}$ & $\begin{array}{l}\text { Distal } \\
\text { latency } \\
(m s)\end{array}$ \\
\hline \multirow[t]{3}{*}{6 Days } & Frontalis & . . . & No & SO & 3.8 & .. & No & Nil & 5.5 \\
\hline & Orb. oculi & $\div+\div$ & No & IP & $\ldots$ & $\cdots \quad:$ & No & IP & - \\
\hline & Orb. oris & $\therefore$ & Yes & Mixed & 3.5 & · : : & No & IP & 3.9 \\
\hline \multirow[t]{3}{*}{13 Days } & Frontalis & ++ & Yes & SO & 5.5 & & Yes & Nil & 4.8 \\
\hline & Orb. oculi & $+\ldots$ & No & IP & -- & i : $\quad \vdots$ & No & IP & -- \\
\hline & Orb. oris & : & Yes & IP & 3.8 & & No & IP & 3.4 \\
\hline \multirow[t]{3}{*}{27 Days } & Frontalis & + & Yes & IP & 4.5 & $\therefore$ & No & IP & 4.8 \\
\hline & Orb. oculi & $\div$ & No & IP & - & & No & Mixed & - \\
\hline & Orb. oris & $\ldots$ & No & Mixed & 3.8 & & Yes & IP & 3.8 \\
\hline \multirow[t]{3}{*}{34 Days } & Frontalis & $\ldots$ & Yes & IP & 4.4 & & No & IP & 4.2 \\
\hline & Orb. oculi & & No & IP & - & Nil & No & IP & - \\
\hline & Orb. oris & Nil & No & IP & 3.4 & $\because$ & Yes & IP & 3.4 \\
\hline
\end{tabular}

SO - Single oscillations. IP $=$ Interference pattern. Normal distal latency. $<4 \mathrm{~ms}$. 
cases. Normal nerve conduction times and 'abnormal complex activity of the involved muscles' suggested that paralysis was compatible with a nuclear lesion. Farquharson (1972), in a case with facial palsy, found positive sharp waves but no fibrillations during the fourth week when the patient was recovering. Garcia-Mullin and Daroff (1973), also in a case with facial palsy, found prolonged distal latencies early in the disease. Abnormal muscle action potentials seen at rest disappeared on applying nerve block. A second EMG at six weeks was normal. A peripheral nerve lesion was postulated but a nuclear lesion with involvement of the larger motor neurones was also considered. Vakil et al. (1973) reported 22 cases and clinically described the complex features noted in the present paper. However, the conclusion from their electrophysiological studies was singular, since it stated that no denervation lesion or true paralysis existed in cephalic tetanus.

Our results indicate that the first type of spontaneous activity (see Results) correlated well with the typical muscle spasm of tetanus. The signals retained their amplitude and form when observed over a period of time. They were abolished by nerve block and, therefore, arose from nerve impulses. However, whether the signals always represented so-called motor units was unclear. On occasions they appeared compatible with the firing of single muscle fibres.

Denervation potentials were recorded in 26 muscles from 10 patients who showed paralysis. That they were not found in all weak muscles we attributed to two factors. Firstly they presented for a limited period extending from the end of the first to the end of the sixth week of illness. The timing of the electrophysiological studies was, therefore, critical. Secondly, it was difficult to distinguish denervation potentials from a background of the first type of spontaneous activity. Nerve block was used on four occasions to show that denervation potentials persisted. In other cases serial EMGs helped to clarify the issue. Denervation potentials were confined to clinically weak muscles that failed to develop interference patterns on maximum effort. Vakil et al. (1973) also reported an absence of interference patterns from weak muscles. However, they did not attribute this to infranuclear palsy because of lack of other supportive evidence. They suggested that the failure resulted from some abnormality at the central synaptic level, but we have no data to support such an idea. High frequency discharge was seen in two patients who showed evidence of denervation and marginally prolonged distal latencies. Such pseudomyotonia is an occasional but recognised finding in lesions of the lower motor neurone.

The distal latencies of muscles stimulated indirectly were marginally prolonged in eight muscles from four patients. These muscles were also weak, demonstrated denervation potentials, and failed to give interference patterns on maximal effort. The amplitudes of their $\mathbf{M}$ responses were relatively reduced. The latencies returned to normal with resolution of the disease.

Thus, sufficient evidence exists to support a lower motor neurone paralysis in paralytic cephalic tetanus. Segmental demyelination appears an unlikely cause as the marginally increased latencies reverted to normal together with the clinical paralysis in only six to 12 weeks. The finding of selective involvement of muscles, with some paralysed and others normal or overactive, might be explained by a nuclear lesion. A block at the endplate zone cannot be ruled out, as the majority of muscles could not achieve the resting state before being subjected to trains of supramaximal stimuli.

Kryzhanovsky (1975) has suggested that tetanus toxin may affect the actin-myosin-like protein that is a component of microtubules in neurones. If so, carriage of substances down the axoplasm could be impaired without significantly altering nerve conduction. This would result in interference with impulse formation and with the action of trophic substances that normally suppress muscle membrane irritability (Engel and Warmolts, 1973). Our results may be the expression of some such mechanism.

Finally, an explanation must be offered to account for the contrasting overactivity and paralysis seen in facial muscles. Paralysis if present is always maximal next to the site of injury. Toxin formed at this site is assumed to travel along the peripheral nerve to the central nervous system. The largest dose is, therefore, directed to neurones supplying the area of the face closest to the injury. It is proposed that large concentrations of toxin cause paralysis while lesser concentrations produce overactivity by abolishing central inhibition. This view is compatible with our observation that as paralysis wears off it is succeeded by spasm. While facial paralysis appears to be a consequence of a higher toxin concentration it is also evident that facial nerve neurones are unduly susceptible to this effect. Thus, in cases where sufficient toxin diffused in the brain stem to produce contralateral facial paralysis, muscles supplied by other cranial nerves were seen to remain in spasm. Paralytic facial tetanus, therefore, cannot imply an overall high 
concentration of toxin in the central nervous system. This view is endorsed by our mortality statistics which indicate a favourable prognosis for cephalic tetanus as compared with the generalised disease.

\section{References}

Achari, A. M. (1973). Facial palsy in tetanus. British Medical Journal, 3, 543-544.

Brooks, V. B., Curtis, D. R., and Eccles, J. C. (1957). The action of tetanus toxin on the inhibition of motor neurones. Journal of Physiology (London), 135, 655-670.

Duchen, L. W., and Tonge, D. A. (1972). The effects of tetanus toxin on neuromusclar transmission and on the morphology of motor end plates in the mouse. Journal of Physiology (London), 228, 157172.

Engel, W. K., and Warmolts, J. R. (1973). The motor unit. In New Developments in Electromyography and Clinical Neurophysiology. Edited by J. L. Desmedt, pp. 141-177. Karger: Basel.

Farquharson, R. G. (1972). Cephalic tetanus. Proceedings of the Royal Society of Medicine, 65, 875-876.
Garcia-Mullin, L. and Daroff, R. B. (1973). Cephalic tetanus-a case report with EMG study. Journal of Neurology, Neurosurgery, and Psychiatry, 36, 296-301.

Kaeser, H. E., and Saner, A. (1970). The effect of tetanus toxin on neuromuscular transmission. European Neurology, 3, 194-205.

Kryzhanovsky, G. N. (1975). New data on the action of tetanus toxin. In Proceedings of the Fourth International Conference on Tetanus, Dakar, pp. 205210. Foundation Merieux: Lyon.

Mellanby, J., and Thompson, P. A. (1972). The effect of tetanus toxin at the neuromuscular junction of the goldfish. Journal of Physiology (London), 224, 407-418.

Park, D. M. (1970). Cephalic tetanus. Journal of Neurology, Neurosurgery, and Psychiatry, 33, 212215.

Tarlov, I. M., Ling, H., and Zamada, H. (1973). The effect of high doses of tetanus toxin on the motor cells of the spinal cord. Neurology (Minneapolis), 23, 581-590.

Vakil, B. J., Singhal, B. S., Pandya, S. S., and Irani, P. F. (1973). Cephalic tetanus. Neurology (Minneapolis), 23, 1091-1096. 